\title{
Administração pública voltada para o cidadão: quadro teórico-conceitual ${ }^{*}$
}

\author{
Marcelo James Vasconcelos Coutinho
}

\section{Introdução}

O objetivo deste texto é fazer um levantamento da literatura atualizada, nacional e internacional, sobre a administração pública voltada para o cidadão, que seja um referencial teórico para o estudo de experiências inovadoras na área de atendimento ao usuário. A elaboração desse quadro teórico-conceitual busca fundamentar a análise, classificação e sistematização das experiências de gestão, visando a mudança e melhoria nos serviços prestados ao público.

A administração voltada para o cidadão é um dos principais pressupostos do modelo de administração pública gerencial. Foi só a partir dos anos 80 que teve início, em países da Organização para Cooperação e o Desenvolvimento Econômico (OCDE), principalmente no Reino Unido, Nova Zelândia, Austrália e países escandinavos, a reforma administrativa gerencial, apoiada nos princípios da nova gestão. Nos anos 90, essa reforma se estendeu aos Estados Unidos e ao Brasil. Desde então, constituiu-se um quadro teórico e um conjunto de instrumentos de gestão que, dentro do contexto democrático, visam modernizar o Estado e tornar a administração pública mais eficiente e voltada para o cidadão-usuário (Bresser Pereira, 1999).

O modelo de administração pública gerencial inspirou-se na administração privada, mas manteve uma distinção fundamental que é a defesa do interesse público. Dentro do modelo gerencial, a melhoria da qualidade dos serviços prestados ao cidadão assume um papel muito importante. Tratou-se de abandonar o caráter auto-referido da administração burocrática, voltada exclusivamente aos interesses do aparelho do Estado, para

Marcelo James Vasconcelos Coutinho é bacharel em Ciência

Política, consultor e mestrando em Relações Internacionais no Instituto de Ciência Política da Universidade de Brasília.

Contatos: marceloj@unb.br 
colocar em prática as novas idéias gerenciais, oferecendo à sociedade um serviço público de melhor qualidade, em que todas as atenções são centradas nos cidadãos. Vale notar que o caráter mais democrático da nova gestão pública faz referência exatamente à sua orientação ao público, além da participação dos cidadãos e controle social da gestão.

A profunda transformação nas relações entre a administração pública e seus usuários deve-se, em grande medida, à crise do atendimento ao cidadão. Usuários de serviços públicos se mostravam, recorrentemente, insatisfeitos com a qualidade do atendimento. Além disso, os cidadãos exigem, cada vez mais, a prestação de serviços de qualidade que consigam dar resposta às suas demandas crescentes (Pleguezuelos, 2000). Por esses motivos, a prestação de serviços tornou-se um fator bastante crítico para a administração pública no Brasil e no mundo. As razões para a insatisfação com os serviços prestados passam, entre outros problemas, pela ineficiência e ineficácia do atendimento. Por sua vez, a falta de conhecimento e a resistência à adoção dos instrumentos necessários para a melhoria do atendimento dificultam qualquer mudança significativa nessa área.

A administração pública tenta hoje solucionar esses problemas trazendo o cidadão para o centro das suas atenções e preocupações. $\mathrm{O}$ conjunto de mudanças no setor público, implementadas atualmente por muitos países, tendo em vista as expectativas crescentes da sociedade, concentra-se, então, na figura do usuário. Com isso, uma parte importante dos problemas trazidos à administração pública passa a ser resolvida com mais facilidade, olhando mais atentamente para fora das organizações e, conseqüentemente, para aqueles que usufruem dos seus serviços. Além disso, a administração pública voltada para o cidadão é auxiliada hoje pelas transformações tecnológicas que possibilitam o uso de uma série de instrumentos novos para o atendimento. Os avanços na informática, redes e softwares, e nas telecomunicações trazem grandes benefícios para essa mudança do modelo administrativo.

Para cumprir o seu objetivo, o texto será dividido em sete seções, às quais se seguem, no final, algumas orientações adicionais para o bom entendimento. Na primeira seção, serão retratadas as origens da administração pública voltada para o cidadão, bem como o seu desenvolvimento conceitual. A segunda seção apresenta o conceito de qualidade como satisfação do cidadão, enquanto que a seção seguinte discute o papel da inovação nessa área. A quarta seção trata da cultura da prestação de serviços como um fator-chave para a mudança no modelo administrativo. Em seguida, serão apresentadas as principais estratégias para a mudança nos serviços públicos. Finalmente, a sexta e a sétima seções apresentam, respectivamente, os modelos de planejamento e implementação de projetos que visam melhorar o atendimento ao público, e os modelos de atendimento single-window que traduzem as principais tendências internacionais. 


\section{Foco no cidadão: princípios e desenvolvimento conceitual}

A administração pública voltada para o cidadão-usuário tem origem ainda nos anos 80. Em 1987, a OCDE publica um documento, intitulado Administration as Service, the Public as Client, que traz alguns princípios gerais dessa nova administração. Segundo esse documento, os clientes devem saber como a administração funciona, o que a constrange, como é controlada e quem são os responsáveis. Além disso, a administração deve possibilitar a participação dos clientes, satisfazer suas necessidades e ser, ao máximo, acessível ao público.

Contudo, é somente durante a década de 90 que a administração com foco no cidadão se desenvolve mais, espalhando-se para outros países como o Brasil e os Estados Unidos. ${ }^{1}$ Em setembro de 1993, o presidente dos Estados Unidos, por meio de uma Ordem Executiva, estabeleceu as bases para a adoção, pelo governo federal, de uma administração centrada no cliente, instituindo que as agências adotassem uma série de medidas como, por exemplo, a possibilidade de escolha aos clientes, em termos de fontes de serviço, e a promoção de meios de endereçar suas reclamações (Cavalcanti e Otero, 1997). Essa nova política é reforçada por documentos publicados posteriormente, inseridos no programa National Performance Review, em que o cliente é colocado em primeiro lugar (Clinton e Gore, 1995). O National Performance Review falava em reinventar o Estado. Sua idéia central não era diminuir o Estado a qualquer preço, mas torná-lo mais eficiente e orientado para o cidadão-cliente.

As reformas em curso pelo governo americano, bem como em outros países da OCDE, com o enfoque voltado para os clientes inspirouse bastante na perspectiva empresarial. Uma das principais razões alegadas para tratar as pessoas com a mesma atenção que as empresas privadas dispensam à sua clientela se deve, exatamente, ao sucesso que algumas dessas empresas obtiveram implantando um programa que valorizava as necessidades dos clientes. Nesse sentido, o foco no cidadão na administração pública, assim como todo o modelo gerencial, teve inicialmente grande influência de uma mentalidade do mercado, passando a adotar técnicas e métodos da administração de empresas. Essa abordagem tem tido um impacto tão grande nas organizações públicas, que o primeiro passo geralmente tem sido identificar quem é o cliente, compreendido como as pessoas que usufruem dos serviços públicos.

Para muitos autores, é fundamental para a reforma gerencial que os cidadãos sejam vistos como clientes (customers). Nesse sentido, a importação do termo cliente da administração de empresas constitui um avanço também para a cidadania. "Ver o cidadão como um cliente significa apenas dar-lhe a devida atenção, dedicar-lhe o respeito que ele não tem nas práticas 
da administração pública burocrática, auto-referida, voltada para seu próprio poder" (Bresser Pereira, 1999: 122). Assim, a orientação para o cliente significa atender às suas necessidades e respeitá-lo, sem usurpar seu direito de participar nas tomadas de decisão de políticas públicas.

Dentro dessa perspectiva, as organizações públicas mudam de comportamento quando voltam-se para os seus clientes. Elas se tornam mais eficientes e preocupadas com a qualidade dos serviços que prestam ao público, ao ponto de não somente satisfazer as expectativas dos clientes como também superá-las por meio da competição. A criação de um ambiente altamente competitivo entre as organizações públicas, nos moldes do mercado, suscita a valorização máxima do cliente. Segundo Osborne e Gaebler (1994), em uma administração pública tradicional, a maioria dos clientes tem poucas alternativas para os serviços oferecidos pelo governo, o que leva os gestores a ignorá-los. Desse modo, os administradores públicos se esforçam para satisfazer aos grupos de interesse, ao Congresso e ao Executivo, em detrimento dos seus verdadeiros clientes, criando, assim, uma distorção insuportável. Essa é a razão para a administração pública adotar as práticas administrativas das empresas privadas bem-sucedidas.

Contudo, nos últimos anos, é cada vez mais utilizado o conceito de administração com foco no cidadão, ao invés de cliente. Isso ocorre pela percepção crescente de que, no setor público, o critério de eficiência está subordinado ao critério democrático (Cunill Grau, 1997). Assim, ao mesmo tempo em que é preciso construir uma administração pública eficiente, é necessário preservar prioritariamente os valores democráticos. Da mesma forma, a importação de práticas e conceitos organizacionais do setor privado não deve suplantar o objetivo maior do Estado que é o interesse público. A especificidade original do setor público está no seu caráter eminentemente político. Dessa forma, enquanto o setor privado é regido pelo mercado e o lucro, a administração pública não pode ser compreendida fora dos princípios do poder e da legitimidade. Isso faz com que a cidadania assuma uma importância infinitamente maior no setor público, onde o "cidadão-cliente é um cidadão-cidadão, um cidadão pleno, que é o objeto dos serviços públicos e também seu sujeito, na medida em que se torna partícipe na formação das políticas públicas e na avaliação dos resultados" (Bresser Pereira, 1999: 118).

As críticas feitas ao conceito de cidadão como cliente e de governo orientado pelo cliente são inúmeras. ${ }^{2}$ Hirschmann (1999) divide essas críticas em três categorias. Duas delas são bastante pertinentes ao desenvolvimento conceitual da administração pública com foco no cidadão. ${ }^{3}$ O primeiro forte motivo para a rejeição da idéia dos cidadãos transformados em clientes é porque ela marginaliza a cidadania, distanciando o 
público do governo. Isso ocorre quando ao tratar cidadão como cliente, o

governo deixa de ser parte de uma entidade maior que é o público, ou seja, a administração abandona a noção de "nós" e adota a noção de "eles", transformando os cidadãos de proprietários da coisa pública em clientes do governo. Além disso, o foco no cliente torna a satisfação individual mais importante do que o sentido de comunidade, o que transforma o governo em uma espécie de instrumento de consumo (service delivery agency).

Outro problema apontado pelos críticos à idéia dos cidadãos como clientes é que ela simplifica demasiadamente a realidade multifacetada das relações entre a sociedade e o governo. Os incentivos dos servidores públicos em responder às demandas do "cliente" são muito diferentes dos incentivos encontrados no setor privado. Enquanto o agente no setor privado é motivado pelos negócios, os incentivos encontrados na burocracia são diversificados e variam bastante. Por sua vez, o governo e suas agências têm múltiplos "clientes", com múltiplos níveis de interesse, que estão em constante mudança. Os supostos clientes da administração pública não somente têm diversas opiniões e competem por demandas, como eles também jogam papéis diferentes no relacionamento com o governo. Por consequiência, os clientes podem dirigir o governo em diferentes, e muitas vezes opostas direções para servir aos seus interesses. Isso demonstra haver um número de fatores que problematizam as relações da administração pública com os "clientes".

Apesar de todas essas críticas, autores importantes ainda trabalham com a idéia de cidadão como cliente. Osborne e Plastrik (1997) salientam que as organizações públicas, particularmente o governo americano, freqüentemente, fazem uma grande confusão com o conceito de cliente (customer), o que suscita a maioria dos problemas a esse respeito. Às vezes, o cliente é visto como o público em sentido mais amplo. Segundo os autores, isso é verdade quando o produto ou o serviço prestado é um bem público, tais como as políticas de proteção ambiental e de defesa. Por outro lado, quando o bem é privado como, por exemplo, os programas de recreação, o cliente é o indivíduo, a família ou um determinado grupo. Porém, muitos serviços públicos, talvez a maior parte deles, combinam ambos os aspectos, públicos e privados, como acontece com as políticas de educação e saúde. Outra fonte de confusão apontada pelos autores está na diferença entre as organizações que servem membros do público e aquelas que servem outras organizações públicas.

Na visão de Osborne e Plastrik (1997), existem quatro definições que precisam ficar bastante claras na administração com foco no cliente. A seguir, reproduzo o quadro com essas definições. Observa-se que os autores fogem da concepção generalista de cliente, definida de forma imprecisa por Clinton e Gore (1995), como todas as pessoas que usam 
algo que é produzido pela administração pública, ou melhor, as entidades ou indivíduos que são diretamente servidos por um determinado departamento ou agência do governo. Para Osborne e Plastrik (1997), o problema com essa definição é que ela deixa entender que as pessoas sujeitas às leis e regulações seriam os clientes das organizações públicas. Nesse sentido, os criminosos seriam os clientes da polícia, assim como os motoristas seriam os clientes das patrulhas rodoviárias, o que não é verdade.

\section{Definições: clientes, complieres e stakeholders}

Clientes primários: indivíduo ou grupo cujo trabalho da administração pública é primordialmente desenhado para ajudar.

Clientes secundários: outros indivíduos ou grupo cujo trabalho da administração pública é desenhado para beneficiar, mas menos diretamente do que os clientes primários.

Compliers: aqueles que devem se submeter a leis e regulamentações, por exemplo o contribuinte em relação à Receita Federal.

Stakeholders: indivíduos ou grupos que têm interesse no desempenho do sistema ou organização pública, por exemplo, os professores nas escolas públicas.

Apud Osborne e Plastrik, 1997: 182.

Osborne e Plastrik (1997) ressaltam ainda que, para o governo, os cidadãos são mais importantes do que os clientes, da mesma maneira que a accountability para representantes eleitos pelos cidadãos é mais importante do que o controle dos clientes. Isso é a principal causa de confusões conceituais, porque cria uma espécie de accountability dual, baseada na idéia de que os usuários são, ao mesmo tempo, cidadãos e clientes. Na concepção dos autores, o conceito de cidadão como cliente permanece válido quando se trata da influência exercida sobre os resultados ou produtos concretos das atividades da administração pública, ou seja, seus serviços. Isso não exclui ou diminui a qualidade do cidadão, pois não incide sobre a formação de governo e a formulação de políticas públicas, que são aspectos relacionados à cidadania. Assim, fazem pouco sentido as críticas dirigidas ao conceito de cidadão-cliente já apresentadas.

No entanto, é importante notar que as definições de Osborne e Plastrik não resolvem todo o problema. $\mathrm{O}$ conceito de cidadão-cliente ainda carrega princípios de mercado pouco adaptados ao setor público. Como se sabe, o mercado valoriza o lucro e, por isso, acaba criando diferenças entre os clientes. Há inúmeras experiências dessa diferenciação que podem ser lembradas. Alguns bancos, por exemplo, estabelecem duas filas para o atendimento no caixa, uma para os clientes especiais ou "cinco estrelas", e a outra para os demais clientes. Também não é 
incomum algumas concessionárias de carro atenderem mais rapidamente

e com maiores regalias os clientes que compram carros luxuosos, em comparação aos compradores de carros populares. Essas diferenciações entre clientes podem ocorrer com uma certa freqüência nos mais variados ramos do comércio, mas, no setor público, elas são inadmissíveis, pois a igualdade é um princípio essencial.

Graham e Phillips (1999) têm demonstrado, com base no caso canadense, a necessidade de inserir outras dimensões de cidadania à chamada revolução orientada para o cliente (customer revolution). Esses autores concluem os seus estudos, apontando um conjunto de princípios desenhados para manter o engajamento dos cidadãos como parte da administração pública nos três níveis de governo. Não se trata de sugerir que os governos devam abandonar seus esforços para melhorar o serviço prestado ao público, mas lembrar que a revolução orientada para o cliente não deve afetar princípios básicos da administração pública em um contexto democrático. Assim, novas formas de sustentar as relações entre cidadão e suas organizações precisam ser identificadas e cultivadas. Princípios como igualdade, transparência e legitimidade devem guiar sempre o desenvolvimento de quaisquer práticas administrativas. Por essas razões, hoje se utilizam, cada vez mais, expressões como foco no cidadão (citizens focus ou citizens-centred service), cidadão em primeiro lugar (citizens first ou citizen's charter) e administração voltada para o cidadão. $\mathrm{O}$ desenvolvimento conceitual dessa área levou à combinação de algumas práticas e conceitos do mercado com o princípio de cidadania. Nesse sentido, opta-se pelo termo cidadão, incluindo na sua definição todos aqueles que se beneficiam direta ou indiretamente por um serviço público. ${ }^{4}$

A administração pública voltada para o cidadão pode ser definida como um modelo gerencial cujo objetivo é oferecer serviços públicos de maior qualidade, atendendo melhor às demandas dos seus usuários. Como já foi visto, a administração pública voltada para o cidadão (citizen-centred service) é diferente da administração centrada no cliente (customercentred service). Os cidadãos podem ser ou não usuários de serviços públicos específicos, mas são parte de toda uma comunidade e, portanto, contribuem e recebem benefícios da administração pública. Os cidadãos são também portadores de direitos e deveres e, ao contrário dos clientes do setor privado, freqüentemente não podem escolher um serviço alternativo, caso estejam insatisfeitos com o serviço prestado pelo setor público. Assim, funcionários públicos não atendem somente aos usuários diretos, mas preservam os direitos de todos os cidadãos. Isso significa que eles equilibram os objetivos potencialmente conflituosos de satisfação dos usuários com a proteção dos interesses de toda a comunidade ou cidadãos de um país. Essa é a principal razão por que fornecer serviço de alta qualidade no setor público é muito mais difícil do que no mercado. ${ }^{5}$ 
Há uma grande variedade de autores e documentos que discutem os princípios, instrumentos e conceitos da nova administração pública voltada para o cidadão. Contudo, vale destacar alguns pressupostos-chave apresentados por Bertrand de Quatrebarbes (1996) que, de certa maneira, estão subjacentes a toda essa literatura e resumem a mudança do modelo administrativo. Em primeiro lugar, a nova administração voltada para o cidadão admite as especificidades dos serviços públicos, como a participação, a influência do processo político, a legitimidade das decisões e a defesa do interesse público. As discussões levaram ao reconhecimento dos méritos tanto da administração privada quanto da pública, mesmo que as qualidades de eficiência e eficácia na gestão não tenham sido ainda completamente alcançadas no setor público.

Em segundo lugar, a nova administração pública torna as missões e objetivos das organizações baseados em contratos, colocando o cidadãousuário no centro das preocupações das agências e departamentos do Estado. Isso significa que é a partir de "contratos" negociados com a sociedade que os serviços públicos tornam seus critérios de gestão mais claros e precisos, atrelando os recursos humanos, financeiros e logísticos às demandas dos cidadãos. Essa é uma longa empreitada que requer mudanças culturais importantes e uma ação coordenada. Portanto, não pode confinar-se às iniciativas de indivíduos isolados.

Outro pressuposto da administração pública voltada para o cidadão é o de fomentar as condições e instrumentos de gestão necessários à mudança. Instrumentos de troca de experiências, de difusão da informação, de evolução cultural e de capacitação, entre outros, são fundamentais para pôr em prática os conceitos adotados pelo novo modelo administrativo. As avaliações dos resultados, dos processos e da opinião do público também são imprescindíveis para saber se os serviços estão satisfazendo os usuários. ${ }^{6}$

Finalmente, o quarto pressuposto da nova administração pública voltada para o cidadão é fazer prevalecer o diálogo, a transparência e o engajamento. Assim, esse modelo, para dar certo, supõe que seja adotada uma relação de responsabilidade, apoiada na transparência e acordo entre os atores para resolver os problemas que se impõem. Para isso, é preciso coragem, comprometimento e muita vontade de transformar o estado de coisas, em favor da melhoria dos serviços públicos. Todos esses requerimentos, apresentados até aqui, suscitam a adoção de uma série de procedimentos e cuidados que serão discutidos mais adiante no trabalho. Antes, é preciso definir melhor o conceito de qualidade, o que será feito na seção a seguir.

\section{Qualidade como satisfação do cidadão-usuário}

A literatura sobre administração de empresas costuma definir de diferentes formas o conceito de qualidade. Ruy Shiozawa (1993), por 
exemplo, descreve em seu livro alguns componentes gerais do conceito de qualidade dentro da nova organização voltada para os clientes. Embora esses componentes do conceito sejam aplicados principalmente ao setor privado, servem como um ponto de partida para compreender a qualidade na administração pública voltada para o cidadão. Nesse sentido, para o mercado, a qualidade baseada no usuário:

“(...) incorpora elementos subjetivos pautados na satisfação de preferências do consumidor. Na visão de Marketing é a combinação precisa (ponto ideal) dos atributos do produto que possibilitará a máxima satisfação de determinado consumidor. Na visão de administração da produção é a adequação para o uso. Produtos de alta qualidade são aqueles que satisfazem a maioria dos consumidores" (Shiozawa,1993).

O conceito de qualidade varia bastante ao longo da história da teoria administrativa. Do controle clássico de qualidade, como forma de detectar desajustes em especificações técnicas de um produto, passou-se a definir qualidade como o conjunto de características de um produto ou serviço que satisfazem as necessidades e expectativas do cliente (Pleguezuelos, 2000). Segundo Shiozawa (1993), qualidade pode ser minimamente definida como a maximização do sucesso do cliente. Adotar esse conceito significa, quanto à estruturação de um programa de qualidade, orientar todas as demais ações da empresa, internas ou externas, para a satisfação dos clientes. Shiozawa sintetiza as bases das estratégias de uma organização voltada ao atendimento do cliente em três categorias: qualidade como maximização do sucesso do cliente; atendimento ao cliente como diferencial competitivo; e tecnologia de informação gerando soluções.

A Administração de Qualidade Total (Total Quality Management - $T Q M$ ), inverte todos os conceitos tradicionais da administração. Nela, os clientes passam a ser as pessoas mais importantes para a organização. Só depois vêm os interesses dos que servem ao cliente e os da própria administração (Osborne e Gaelbler, 1994). Além disso, a Administração de Qualidade Total enfatiza a constante mensuração e melhoria nos serviços prestados. Esta idéia de qualidade tem sido incorporada à esfera pública, na qual o cidadão pode ser considerado como usuário, na medida em que é receptor da ação das organizações públicas. Assim, qualidade passa a significar a satisfação das necessidades e expectativas dos cidadãos, supondo ainda a redução dos custos e a melhora permanente dos processos de acordo com as exigências da sociedade. 
Fundamentos da administração
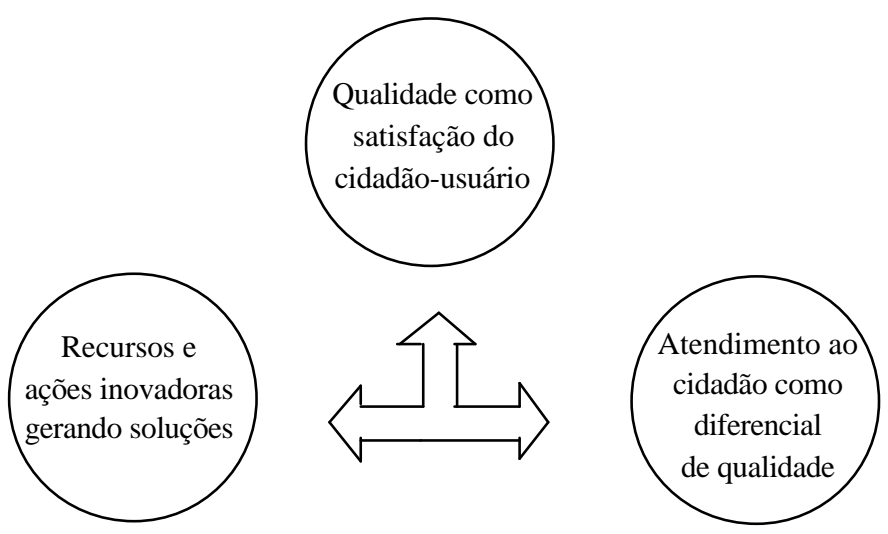

Qualidade supõe, portanto, maior eficácia e eficiência. Isto é, supõe que os serviços prestados ao público tenham um impacto real nas suas necessidades e expectativas, enquanto melhora a relação entre os recursos empregados e os resultados obtidos (Pleguezuelos, 2000). As implicações do conceito de qualidade total para a administração pública são muitas. Uma das principais consequiências é a ampliação do conceito de cliente, considerando o cidadão como um cliente que recebe serviços, ao mesmo tempo em que se concebe a organização como um sistema integrado de provedores e clientes internos. Além disso, como foi visto anteriormente, os cidadãos não perdem sua característica de indivíduos politicamente responsáveis, participativos e parte integrante do setor público. Assim, é possível adaptar as categorias do esquema de Shiozawa (1993) às especificidades da administração pública, fazendo algumas pequenas alterações que são apresentadas no esquema acima.

O que os fundamentos da nova administração pública voltada para o cidadão mostram é que, se a qualidade dos serviços de uma organização depende da satisfação do usuário, então, o seu atendimento deve ser sempre o melhor possível, fazendo com que haja um diferencial qualitativo substancial. Para isso, é preciso adotar ações inovadoras capazes de mobilizar todos os recursos disponíveis em busca de soluções eficientes e eficazes, dentro do processo de trabalho das organizações públicas.

Porém, como medir a qualidade dos serviços prestados ao cidadão? Evidentemente a resposta está na satisfação dos usuários. De acordo com o conceito adotado neste trabalho, cidadãos-usuários satisfeitos é sinal de boa qualidade nos serviços prestados pelas organizações. Quanto maior a satisfação do usuário melhor é a qualidade do atendimento e cumprimento das expectativas do público. Agora, como mensurar a satisfação do usuário? Existem diferentes maneiras para fazer isso ${ }^{7}$, mas uma 
forma bastante simples é ouvindo o cliente por meio de questionário que aponte o grau de satisfação com o serviço, os principais obstáculos e facilidades, expectativas e possíveis formas de melhorar o atendimento.

Uma pesquisa realizada no Canadá mostra as expectativas dos cidadãos quanto ao atendimento (Erin Research Inc, 1998). Os resultados desta pesquisa podem servir como bons indicadores de qualidade. Eles encontram-se resumidos no quadro seguinte:

\section{Padrões de qualidade do atendimento ao público}

\begin{tabular}{l|l|l|c|c}
\hline & Telefone & Guichê & Correio & E-mail \\
\hline $\begin{array}{l}\text { Número máximo de pessoas } \\
\text { com as quais o usuário } \\
\text { precisa lidar }\end{array}$ & 2 pessoas & 2 pessoas & - & - \\
\hline $\begin{array}{l}\text { Tempo máximo para retornar } \\
\text { à solicitação do usuário }\end{array}$ & 4 horas & - & 2 semanas & 4 horas \\
\hline $\begin{array}{l}\text { Tempo aceitável para } \\
\text { esperar em uma fila }\end{array}$ & - & - & 5 minutos & - \\
\hline
\end{tabular}

Fonte: Erin Research Inc, 1998.

Vale ressaltar que, a rigor, os padrões de bons serviços aos cidadãos devem ser obtidos com os próprios usuários, verificando o que desejam. Portanto, passa a ser crucial a realização de pesquisas junto aos cidadãos-usuários, para se obter informações a respeito de suas necessidades, bem como sobre formas de melhorar o atendimento. Muitos países já realizam pesquisas rotineiras junto aos usuários de serviços públicos. No Brasil, essa iniciativa é bem recente, sendo que apenas no ano de 2000 foi concluída a primeira Pesquisa Nacional de Avaliação da Satisfação dos Usuários de Serviços Públicos. Contudo, os indicadores mostrados no quadro acima devem servir, inicialmente, para orientar as organizações públicas, no sentido de que elas possam já avaliar o grau de qualidade dos serviços que vêm prestando aos cidadãos com base nos padrões internacionais de atendimento.

Vale ainda destacar oito recomendações feitas pela presidência americana à suas agências governamentais. Elas são baseadas nos princípios fundamentais da Carta ao Cidadão (Citizen's Charter, 1995), que inspirou iniciativas em muitos países como os Estados Unidos, Canadá, França, Bélgica, Austrália e Itália (Osborne e Plastrik, 1997). Com essas recomendações, as organizações públicas passam a ter obrigação de: 1) identificar quem são os seus usuários; 2) realizar pesquisas junto a esses usuários para determinar suas expectativas quanto ao tipo e qualidade 
dos serviços; 3 ) estabelecer padrões de qualidade e compará-los à situa-

ção atual; 4) buscar comparações com o desempenho de serviços prestados na iniciativa privada (benchmark); 5) realizar pesquisa junto aos funcionários públicos para detectar obstáculos e outros problemas para melhorar os serviços; 6) possibilitar opções de fontes de serviços aos usuários; 7) tornar as informações, serviços e sistemas de queixas facilmente acessíveis aos cidadãos-usuários; e 8) providenciar retornos rápidos e eficazes às reclamações dos usuários (Osborne e Plastrik, 1997).

\section{Inovação a serviço da qualidade}

O conceito de inovação foi desenvolvido, originalmente, para responder às necessidades de políticas de ciência e tecnologia integradas às políticas econômicas, visando uma maior competitividade internacional. Assim, o termo inovação servia para designar estritamente mudanças tecnológicas. Desde então, o conceito se ampliou bastante e, atualmente, inclui a organização e a gestão do trabalho, formas diferentes de educação continuada, o desenvolvimento de novas formas de relações capital/trabalho e organização/cliente, a descentralização produtiva, administrativa e política e formas cooperativas de gestão e investimento social, entre outras áreas (Rua, 1999).

A inovação pode ser bastante simples ou extrema, trazendo desde pequenas modificações de procedimento até uma forma inteiramente nova de trabalho, geralmente relacionada ao avanço da tecnologia. Além disso, as inovações podem ser cumulativas, levando a um processo de melhoria contínua. Finalmente, a inovação atinge diferentes áreas e resultados. Ela pode afetar processos de trabalho, produtos específicos ou o modo como a organização é gerenciada, alcançando maior ou menor sucesso. $\mathrm{Na}$ administração pública, o conceito de inovação também assume uma definição bastante ampla, e o seu maior obstáculo, freqüentemente, encontra-se no desestímulo à criatividade (Rua, 1999).

A capacidade de inovar depende principalmente do surgimento de um certo ambiente de inovação, caracterizado pelo conjunto de arranjos institucionais, comportamento político, cultura organizacional, participação e valores sociais (Rua, 1999). Todos esses fatores criam os incentivos e estímulos à inovação. Contudo, é no conhecimento que o mundo de hoje concentra seu grande potencial de mudança. A influência do conhecimento ocorre em todas as áreas da vida humana, constituindo a chamada sociedade da informação. $\mathrm{O}$ conhecimento, aliado à criatividade e ao empreendedorismo, constrói um ambiente inovador, pronto para gerar soluções imaginativas aos problemas enfrentados e suplantar os limites até então impostos. 
A inovação é resultado de um esforço coletivo que envolve uma mudança nas crenças, valores e atitudes de uma equipe de trabalho, e da organização como um todo. Porém, esse esforço só surte efeito quando encontra um contexto democrático, livre e motivador, que permita o uso de novas tecnologias com o comprometimento e participação das pessoas envolvidas. Desse modo, "para que a inovação ocorra, é essencial a democratização do conhecimento e das decisões, implicando descentralização, desconcentração, horizontalização, investimento em capital humano, flexibilização e abertura para a relação com usuários" (Rua, 1999: 286).

Os avanços na tecnologia da informação estão propiciando também grandes mudanças na administração pública. Até mesmo em países em desenvolvimento, como o Brasil, houve um aumento espantoso no número de computadores à disposição dos serviços públicos, juntamente com a formação de redes internas (Intranet) e externas (Internet) que aproximam e integram, cada vez mais, as agências e departamentos do governo e a sociedade. As páginas na Internet (homepages ou sites), por exemplo, oferecem hoje uma imensa quantidade de informação aos usuários dos serviços públicos, possibilitando uma nova forma de atendimento ao cidadão, como também os correios eletrônicos. No Brasil, já temos alguns programas em atividade, ou em fase de implantação, como a rede do governo que permite a intercomunicação dos ministérios. Da mesma forma, aparecem o Sistema de Serviços Gerais (SIASG), Sistema de Administração Financeira (SIAFI), Sistema de Informações Organizacionais (SAIORG) e o Sistema de Gestão de Documentos e Informações (SIGDI). Todos eles compartilham bancos de dados, que são gradualmente abertos ao conhecimento e controle da sociedade (Bresser Pereira, 1999).

As inovações ocorrem também em dimensões menores e bastante objetivas, relacionadas ao cotidiano das organizações e a processos de trabalho relativamente simples. Elas podem ocorrer de muitas outras formas diferentes. A prestação de serviços públicos por meio de Centrais de Atendimento, por exemplo, segue a tendência internacional do uso do one-stop model, ou seja, atendimento generalista em balcões ou quiosques, também chamados de guichê único ( single-window). O guichê único é um modo de prestação de serviço que consiste em reagrupar os serviços públicos ou fornecimento de informações de modo que os cidadãos possam dedicar menos tempo e esforços para tentar obter os serviços de que necessitam. ${ }^{8}$ Este modo de prestação dos serviços cumpre basicamente três funções: 1) melhorar a acessibilidade aos serviços públicos(em geral), à medida que os cidadãos podem receber informações e orientações sobre onde e como obter os serviços desejados; 2) aumentar a comodidade de acesso aos serviços por meio dos centros multisserviço, os quais podem oferecer, em um mesmo lugar, a totalidade ou 
grande parte dos serviços fornecidos por um determinado órgão público (agrupamento de serviços); e, finalmente, 3) ultrapassar os limites das competências (dos órgãos públicos) para fornecer serviços integrados, ou seja, serviços públicos conexos, comuns a diferentes órgãos ou níveis governamentais, fornecidos em um mesmo espaço. Este modelo de serviço costuma oferecer bancos de dados integrados; desenvolvimento de pessoal de atendimento; qualidade e rapidez no serviço; participação do cidadão na manutenção da excelência na prestação dos serviços. ${ }^{9}$

Os postos de serviço itinerantes e as experiências de uso de tecnologias da informação, por sua vez, colocam diretamente o problema da viabilização do acesso aos cidadãos da prestação de serviços públicos. Se por um lado as tecnologias de informação de ponta disponibilizam aos cidadãos-usuários serviços e informações em tempo real, reduzindo a necessidade de deslocamentos, o dispêndio de tempo e dinheiro, o número de contatos para a obtenção dos serviços e o atendimento conclusivo, por outro lado, é necessário que estes cidadãos-usuários tenham acesso prévio aos suportes necessários à obtenção dos serviços: microcomputadores conectados à Internet, acesso a linhas telefônicas, fax etc. O acesso ao suporte tecnológico é um pré-requisito do acesso ao serviço. ${ }^{10}$

Em contrapartida, a forma de prestação dos serviços dos postos de serviço itinerantes, constitui-se justamente em levar atendimento público - disponibilizando um determinado serviço ou conjunto de serviços — até os cidadãos-usuários que não têm condições de buscá-los por si mesmos. Neste caso, o serviço vai até os cidadãos-usuários, levando consigo não apenas os serviços demandados, mas também os suportes tecnológicos (computadores, fax, Internet, arquivos, bancos de dados) necessários para viabilizar a prestação do serviço. Pode-se dizer que esta é uma variante do modelo de atendimento por guichê único. A diferença fundamental, no entanto, é que além de fornecer serviços voltados para as necessidades dos usuários, os postos de serviço itinerantes têm como foco a garantia do acesso aos serviços de maneira equiitativa a todos os cidadãos demandantes, o que ressalta o seu caráter democrático. Todos esses modelos de atendimento serão melhor examinados na última seção do trabalho. ${ }^{11}$

Essas mudanças são movidas pela enorme quantidade de transformações e avanços mundiais, assim como pela necessidade cada vez maior de alcançar níveis mais altos de qualidade nos serviços prestados ao público (Pinto, 1999). Foi visto, na seção anterior, que os recursos e ações inovadoras gerando soluções compõem o segundo dos fundamentos da administração pública voltada para o cidadão. Nesse sentido, toda e qualquer inovação aparece com um objetivo bastante claro que é alcançar 
resultados que melhorem o atendimento ao público. Inovação a serviço da qualidade, e qualidade como satisfação do cidadão-usuário são, portanto, conceitos-chave que formam as bases da nova administração. Resta apresentar o terceiro fundamento, isto é, como o atendimento ao cidadão alcança efetivamente um diferencial de qualidade. Isso será mostrado nas próximas seções do trabalho, por meio da discussão sobre a cultura de prestação de serviços, estratégias, planejamento e implementação da mudança e modelos de atendimento single-window.

\section{Cultura de prestação de serviços}

A mudança cultural é frequientemente um desafio para a nova administração pública. Embora ainda permaneçam muitas dúvidas sobre os prospectos dos esforços de reforma cultural, pesquisadores estão cada vez mais convencidos das vantagens que esses esforços geram para a efetividade e accountability da administração pública. Eles vêm descobrindo o quanto é importante a mudança cultural para o sucesso ou o fracasso na implantação não somente da administração voltada para o cidadão como para todo o resto das transformações do modelo administrativo (Durant, 1999).

A administração voltada para o cidadão é uma mudança conceitual muito importante para a modernização administrativa, que implica na adoção de certos valores, atitudes e crenças compatíveis com os seus preceitos. Nesse sentido, a transformação na administração pública requer não somente mudanças estruturais, de regras e processos, mas também, e fundamentalmente, uma intervenção para criar novos sistemas de valores. Se, por um lado, a reorientação no sentido do cidadão-usuário constitui um poderoso instrumento de transformação do modelo administrativo, por outro, a construção desse modelo só ocorrerá com uma grande mudança cultural. No documento apresentado pela OCDE (Public Management Service, 1996), baseado na experiência portuguesa, são apresentados alguns dos principais impactos que a administração pública voltada para o cidadão causam sobre os sistemas de valores.

Em primeiro lugar, a administração pública voltada para o cidadão adota um sistema de valores democráticos. Cidadãos passam a compreender melhor que a administração pública existe para servi-los, e suas atividades devem ser transparentes e controladas por eles. Em segundo lugar, no novo modelo administrativo, os funcionários tornam-se, efetivamente, servidores do público. $\mathrm{O}$ envolvimento dos cidadãos leva os oficiais e funcionários públicos a redefinirem seus papéis e abandonarem suas atitudes auto-referenciadas em favor da prestação de serviços. E, finalmente, a modernização administrativa orientada para o cidadão retira a 
imagem negativa que cerca os serviços públicos, estabelecendo um ambiente de apoio e confiança entre Estado e sociedade.

A cultura organizacional, embora varie bastante de uma organização para outra, tem características comuns relacionadas a sociedade onde a organização está inserida. Isso vale também para a cultura de prestação de serviços. Ou seja, o estilo do atendimento, normas e padrões típicos, é condicionado pelas práticas dominantes no ambiente sócio-cultural da organização.

De acordo com alguns autores, a administração pública no Brasil deve ser compreendida, em primeiro lugar, a partir das suas heranças patrimonialistas (Martins, 1995). Esse legado político-cultural é baseado na histórica falta de uma divisão clara do poder público e da atividade privada, e na concepção de que o Estado tem como função atender os interesses pessoais e servir lealmente aos chefes políticos, em detrimento da qualidade e eficiência dos serviços prestados ao público. Por sua vez, outros autores demonstram como os padrões culturais, além das instituições e processos políticos, são resultados também de práticas clientelistas e corporativistas associadas com insulamento burocrático e universalidade da norma, originados no Brasil nos anos 30 e 40 (Nunes, 1997). A cultura da administração pública brasileira reflete, assim, um modelo híbrido que combina as administrações pratrimonialista e burocrática (Rua, 1999).

Não obstante os legados patrimonialistas, a literatura destaca pelo menos dois padrões culturais encontrados nas organizações, de modo geral, não somente no Brasil e também não somente no setor público: a cultura tecnocrática e a cultura burocrática (Cardoso e Cunha, 1994). A soma desses dois padrões culturais gera um comportamento do servidor público orientado pelo excessivo formalismo e ritualismo das regras, privilegiando rotinas administrativas departamentalizadas, baseadas em estruturas hierárquicas rígidas e pouco interpessoais que reduzem o comprometimento, a responsabilidade e a criatividade do corpo de funcionários.

"Nas culturas tecnocráticas, predomina a valorização da técnica e das tecnologias; as relações interpessoais são pouco ou não consideradas; é insuficiente o cuidado com as comunicações internas e verifica-se uma tendência a separar as pessoas e unidades organizacionais pelas competências e especializações, investindo-se muito pouco na integração das diferenças. Já nas culturas burocráticas, o investimento predominante é na produção das normas, regras e rotinas de funcionamento; o controle das pessoas, pela via das classificações, das estruturas organizacionais e das hierarquias, é mais forte do que a prática da interação e da negociação; investese pouco nos mecanismos de cooperação e em atividades integradoras, prevalecendo a separação e, mesmo, o isolamento dos grupos dentro dos departamentos, divisões, setores e seções" (Cardoso e Cunha, 1994: 25). 
Ao contrário do que se vê nas culturas tecnocráticas e burocráticas, a cultura de prestação de serviços deve preocupar-se com as relações interdependentes, baseadas na parceria e na cooperação. Além disso, cada unidade da organização deve visar sempre a qualidade do seu trabalho para que isso possa produzir um bom desempenho da organização como um todo. Para Cardoso e Cunha (1994), existem quatro marcas importantes em uma cultura da prestação de serviços: parceria, compromisso, qualidade e efetividade. A seguir apresento um quadro síntese dessas marcas.

\section{Marcas de uma cultura de prestação de serviços}

1) Parceria: significa assumir que o prestador de serviços trabalha em conjunto. Servidor e usuário são pessoas interdependentes, posto que estão envolvidos em um mesmo processo e interagem constantemente um com o outro.

2) Compromisso: aponta para o fato do atendimento estar sempre a serviço de alguém. O servidor trabalha principalmente para atender às necessidades de outros, e não apenas em função de seus próprios interesses.

3) Busca da qualidade: traduz a procura incessante pela excelência, baseada em um conceito de qualidade mais amplo, que inclui primordialmente a satisfação do usuário.

4) Resultados efetivos: significa que a prestação de serviços deve procurar sempre produzir resultados com efeitos visíveis para os usuários, resolvendo seus problemas e satisfazendo realmente suas expectativas.

Apud Cardoso e Cunha (1994).

Esses componentes da cultura de prestação de bons serviços enfatizam que haverá, no atendimento, uma tendência a se desenvolverem mecanismos mais transparentes, com uma circulação maior de informações e descentralização integrada das atividades e decisões. Além disso, segundo esses quatro componentes, quem presta serviços ao público deve ser um especialista em encontrar soluções rápidas e efetivas para os problemas detectados. Por fim, um outro corolário dessas quatro marcas é a ênfase dada à autonomia, como uma qualidade que deve ser privilegiada nos relacionamentos internos e externos da organização. A autonomia está associada a uma prática de auto-responsabilidade que produz nos servidores uma sensação verdadeira de pertencimento à organização, tornando-os, por conseqüência, sujeitos comprometidos e capazes de identificar e solucionar problemas de modo interdependente (Cardoso e Cunha, 1994).

\section{Estratégias para a mudança}

A administração pública voltada para o cidadão requer um novo estilo de trabalho baseado, fundamentalmente, na autonomia do cidadãousuário. Resumidamente, o novo sistema administrativo deve funcionar 
privilegiando a conveniência dos cidadãos-usuários, no sentido de que estes possam ter opções de atendimento e conhecer, com precisão, onde obtêm informações sobre a qualidade e disponibilidade dos vários serviços existentes, podendo, então, escolher aquele de sua preferência. Osborne e Plastrik (1997) apresentam três estratégias básicas que devem tornar as organizações públicas mais accountable dos usuários: conceder o poder de escolha dos serviços ao cidadão (customer choice); fornecer opções competitivas de serviços (competitive choice); e assegurar a qualidade (customer quality assurance).

A primeira estratégia consiste em dar ao usuário o poder de escolher qual organização pública ele prefere utilizar os serviços (customer choice). Isso significa não somente que o cidadão-usuário poderá escolher entre organizações que prestem o mesmo serviço, mas também que não haverá qualquer consequiência negativa dessa escolha. Assim, por exemplo, os pais devem sempre poder escolher em qual escola pública eles colocarão seus filhos. Quando isso acontece abertamente para todos, força as escolas, com o tempo, a melhorarem cada vez mais.

Para Osborne e Plastrik (1997), há um número de critérios básicos para tornar efetiva a estratégia de conceder o poder de escolha aos cidadãos. Antes de mais nada, é preciso que haja uma suficiente oferta de serviços. Nesse sentido, se por acaso o tipo de serviço prestado é naturalmente monopólico, então, essa estratégia deve ser abandonada. Por outro lado, se é razoável haver mais de uma possibilidade de oferta, então, neste caso, a estratégia renderá bons resultados. Em segundo lugar, é preciso que os usuários tenham condições suficientes para gerar uma demanda necessária para produzir uma oferta adequada de prestadores de serviços. Em terceiro lugar, os cidadãos devem requerer informações úteis, acessíveis e confiáveis sobre a qualidade e os custos de diferentes serviços prestados pelas organizações públicas. Um outro critério de efetividade da estratégia de conceder o poder de escolha aos cidadãos é o de que os governos tenham uma estrutura de regras para o setor público, de modo que suas agências sejam constrangidas a obedecê-las, evitando, assim, abusos e outros comportamentos oportunistas. E, finalmente, essa estratégia deverá ser adequada quando os governos forem atentos às questões de eqüidade na estrutura de oferta de serviços públicos. A seguir estão apresentados os principais instrumentos da estratégia de escolha dos cidadãos-usuários.

\section{Instrumentos para a estratégia de escolha dos cidadãos}

Sistema de escolha pública: permite aos usuários de serviços públicos escolherem entre diferentes organizações prestadoras desses serviços.

Sistema e agentes de informação aos usuários: fornece aos cidadãos-usuários informações sobre a qualidade e custos de cada provedor de serviço, possibilitando, assim, escolhas mais fundamentadas.

Apud Osborne e Plastrik (1997). 
A segunda estratégia básica para tornar as organizações públicas mais accountable dos usuários consiste em fornecer opções competitivas de serviços (competitive choice). Essa estratégia está bastante associada com a primeira, que concede o poder de escolha aos cidadãos. Embora esteja limitada pelo leque de serviços oferecidos, ela é freqüentemente a melhor opção para situações de quase mercado (serviços de saúde, educação, treinamento de trabalho, entre outros).

O sucesso das instituições "quase mercado" deve-se aos seus objetivos de trazer as forças do mercado para conduzir a produção de bens e serviços públicos. Em comparação aos monopólios burocráticos da administração pública tradicional, os "quase mercados" costumam ser mais eficientes e mais atentos às preferências dos cidadãos-usuários, posto que são competitivos (Lowery, 1998). Isso significa que a produção de bens e serviços será muito mais orientada pelo que desejam os cidadãos, estabelecendo, assim, a soberania do usuário (consumer soverreignty).

Existem muitas maneiras de adotar a estratégia de escolha competitiva. Porém, de maneira geral, o uso dela implica em oferecer bens públicos dentro de parâmetros de mercado. A primeira tarefa dessa estratégia é se proteger contra a tendência de os provedores de serviço selecionarem o melhor e mais fácil cliente (Osborne e Plastrik, 1997). Ou seja, a estratégia de competitividade deve procurar evitar efeitos perversos, que possam atingir o princípio de igualdade da administração pública. Uma escola pública, por exemplo, que seja avaliada por índice de aprovação de alunos, e dependa desse índice para obter recursos do governo, pode barrar a entrada de alunos com notas baixas por meio de exames de seleção. $\mathrm{Ou}$, mais grave do que isso, certos hospitais podem sacrificar a qualidade do atendimento, expandindo de forma descontrolada o número de leitos, porque por meio desse número são avaliados. Por essa razão, os governos precisam elaborar proteções contra esses efeitos perversos, visando sempre preservar a igualdade de oportunidades. Uma forma de fazer isso é criando mecanismos que obrigam as escolas públicas, em caso de grande demanda de estudantes, a sortearem aleatoriamente os alunos.

Uma outra tarefa da estratégia de escolha competitiva é se proteger contra a propaganda enganosa. Em um mercado competitivo, algumas organizações podem distorcer a realidade durante o processo de divulgação e marketing dos seus serviços, enganando, assim, o cidadão (Osborne e Plastrik, 1997). Para prevenir esse tipo de comportamento, o governo precisa exercer efetivamente seu poder regulador, advertindo e punindo os prestadores de serviço que insistem em informar mal os usuários. Finalmente, uma terceira tarefa da estratégia de escolha competitiva é a de se proteger contra o aumento da segregação de classe e raça (Osborne e Plastrik, 1997). Algumas escolas podem excluir, indiscriminadamente, alunos mais pobres ou constituir guetos raciais de estudantes. 
O governo deve combater, sem limites, esse tipo de comportamento preconceituoso e racista, ajudando a construir uma sociedade mais pluralista, tolerante e integrada. Abaixo, apresento um quadro síntese das principais ferramentas adotadas na estratégia de escolha competitiva.

\section{Instrumentos para a estratégia de escolha competitiva}

Sistema de escolha pública competitiva: encoraja os usuários a escolherem as organizações públicas que lhe prestam serviços, deixando que o dinheiro público siga essas suas preferências.

Programas de reembolso e recibo: confere às organizações públicas escolhidas pelos cidadãos-usuários os recursos auto-administrados, ou o devido reembolso pelo serviço prestado.

Apud Osborne e Plastrik (1997).

Por fim, a terceira estratégia apresentada por Osborne e Plastrik (1997), para alcançar uma administração pública voltada para o cidadão, é a de assegurar a qualidade dos serviços prestados pelas organizações (customer quality assurance). Essa estratégia consiste na criação de regras e padrões de qualidade que forçam as organizações a desempenharem bem o seu trabalho, satisfazendo os cidadãos-usuários. Os princípios da qualidade na administração pública voltada para o cidadão já foram vistos anteriormente no trabalho, em seguida, observam-se os instrumentos que asseguram esses princípios.

\section{Instrumentos que asseguram a qualidade nos serviços públicos}

Padrões de serviço: estabelecimento máximo e mínimo do tempo de atendimento, tempo de espera, tempo na fila, número de funcionários disponíveis etc.

Reparação ao usuário: formas de compensação, inclusive financeira, quando as organizações falham em seus serviços prestados ao público.

Garantia de qualidade: devolução de dinheiro ou outro bem para o usuário que tenha ficado insatisfeito.

Inspetores de qualidade: controle, por profissionais ou não, dos serviços prestados ao público de acordo com os padrões de qualidade já estabelecidos.

Ombudsmen: auxilia os cidadãos-usuários na resolução de suas disputas, e obtém serviços ou informações que eles precisam quando não se sentem satisfeitos com o sistema de reclamações. 
Osborne e Plastrik (1997) lembram também de uma quarta estratégia que seria a capacidade das organizações de conhecer e listar os usuários dos seus serviços, visando a realização de consultas e de controle de desempenho (customer voice). Assim como essas, outras estratégias poderiam ser imaginadas. Contudo, o importante é perceber que elas podem e devem ser, na medida do possível, integradas e utilizadas em conjunto. Além disso, ainda sob as estratégias de mudança, vale destacar o esforço especial pela simplificação do atendimento. Independentemente de haver ou não opções de escolha ao usuário e dos padrões de qualidade estabelecidos, é essencial compreender que todos os serviços prestados ao público devem procurar ser os mais simples e transparentes possíveis.

Uma administração voltada para o cidadão deve livrar o usuário do confronto com um labirinto de programas e repartições, bem como uma infinidade de formulários, documentos e critérios processuais para desfrutar dos benefícios a que tem direito. Ao mesmo tempo, esse modelo administrativo deve gerar sistemas com maior transparência, de forma que os cidadãos-usuários sejam capazes de se mover ou escolher entre muitas opções disponíveis, escapando, então, da burocracia. Por sua vez, é necessário perceber que os usuários de qualquer serviço não estão interessados em conhecer como cada sistema desses funciona por dentro. O que eles desejam apenas é saber como solucionar seus problemas com a maior tranqüilidade e rapidez possível. Assim, uma organização voltada para os cidadãos-usuários devem permitir que eles supram suas "necessidades de forma holística, integrada, sem que tenham de se submeter a uma dúzia de programas diferentes" (Osborne e Gaebler, 1994).

Nesse sentido, vale destacar algumas ferramentas hoje disponíveis às estratégias de mudança com foco no cidadão. Novas formas organizacionais é a primeira delas. Entre agências de controle e de inspeção, estão também as experiências de uma organização que trabalha em parceria com setores voluntários e privados. A tecnologia é outra ferramenta fundamental. Ela tem sido muito importante para melhorar os serviços prestados de maneira genérica, mas em especial o serviço de informação à distância, por meio de programas de computador, bancos de dados, Internet e Intranet. Existem ainda ferramentas como o benchmarking, técnicas de processo de trabalho e de gerenciamento, entre muitas outras que estão à disposição da criatividade de reformadores e gestores da mudança (Blythe e Marson, 1999).

\section{Planejamento, implementação e avaliação}

O primeiro passo para a implantação de melhorias no atendimento ao público é realizar um bom planejamento das mudanças e inovações 
que se deseja fazer. De modo amplo, é possível definir o planejamento como uma forma de "ordenar a ação e programar a construção do futuro" (Cardoso e Cunha, 1994: 67). O planejamento do atendimento no setor público é cada vez mais importante, posto que os cidadãos-usuários estão, a cada dia que passa, mais exigentes em relação à qualidade dos serviços disponíveis. Com isso, é também crescente a necessidade das organizações públicas aperfeiçoarem os serviços oferecidos, respondendo, à altura, à demanda e expectativas dos cidadãos.

Antes de iniciar o planejamento, é preciso levar em consideração que os problemas encontrados podem e devem ser transformados em oportunidade. Isso significa tratar naturalmente os problemas existentes no atendimento, procurando soluções criativas que possam melhorar o serviço. Além disso, é necessário também começar o mais rápido possível a mudança, para que no futuro próximo, elas possam traduzir melhorias reais no atendimento. $\mathrm{E}$, finalmente, todo planejamento não pode perder de vista que a qualidade é um bem que deve estar presente desde o início, na forma e na natureza das informações que fazem o cidadão-usuário optar por um determinado prestador de serviço (Cardoso e Cunha, 1994).

Os estudos feitos pelo Canadian Centre for Management Development (CCMD) (Blythe e Marson, 1999) oferecem importantes lições que devem constar no planejamento de organizações voltadas para o cidadão-usuário. A seguir, é possível observar todas essas lições em um quadro síntese, que pode servir para orientar os planos de reformadores. São muitas as lições apresentadas, mas todas elas são extremamente úteis para tornar os serviços públicos melhores.

\section{Regras para planejar melhorias nos serviços públicos}

As organizações públicas devem:

1. Conhecer bem os usuários dos seus serviços.

2. Realizar pesquisas, buscando novas experiências.

3. Procurar ter apoio político para os seus projetos.

4. Ter uma liderança interna forte.

5. Buscar avaliações (feedbacks) de usuários e servidores.

6. Comunicar suas iniciativas aos servidores e aos usuários.

7. Estabelecer estratégias que traduzam claramente as propostas dessas iniciativas, tanto quanto linhas precisas para a implementação e avaliação.

8. Reunir uma equipe responsável direta e integralmente por essa iniciativa.

9. Assegurar que recursos suficientes serão alocados a essa iniciativa.

10. Capacitar servidores e gerentes com o foco no cidadão. 
11. Buscar melhorias contínuas e permanentes com o desempenho medido sobre o tempo.

12. Desenhar e implementar as mudanças de acordo com o tipo de organização, programa e trabalho realizado.

13. Buscar mudanças simples, menos custosas e demoradas.

14. Identificar e diluir as eventuais resistências à mudança explicando o projeto, motivando os servidores e mostrando a melhora no desempenho.

15. Administrar interesses divergentes por meio de um processo de negociação, trocas e acordos.

16. Esperar um progresso de mudança sempre mais lento e pausado em função das resistências e dos conflitos.

Apud Blythe e Marson, 1999.

Após cumprida a etapa do planejamento, tem início a implementação dos projetos de mudança nos serviços públicos. Vale notar que essa divisão do processo de mudança, planejamento, implementação e avaliação, é importante apenas para fins de análise e de esquematização, pois, na realidade, todas essas etapas estão estreitamente relacionadas. Por exemplo, nem sempre todas as decisões e problemas são antecipados durante o planejamento, o que obriga os gestores a adaptarem o programa de mudança às situações que aparecem ao longo da implementação. $\mathrm{Na}$ verdade, às vezes, essa adaptação não só é possível, como também desejada em casos de conflitos não resolvidos e conhecimento limitado dos planejadores, entre outras situações. Por sua vez, a avaliação, como veremos mais adiante, busca primordialmente melhorar o projeto até então implementado, bem como eventuais novos planos de mudança.

Em geral, a fase de implementação diz respeito a um conjunto de ações necessárias para que uma política, programa ou projeto saia do papel, dos planos de políticos e gestores públicos, e funcione concretamente. Existem casos em que a implementação é mal realizada ou inacabada, devido a uma estrutura complexa de relações internas e externas às organizações públicas. Por isso, para tentar assegurar que a direção e as dinâmicas da mudança nos serviços públicos atendam às expectativas dos reformadores de uma administração pública voltada para o cidadão, é preciso seguir certas regras. A seguir, apresenta-se um quadro com algumas delas, baseadas na experiência portuguesa, que encoraja o esforço de modernização e facilita a introdução das iniciativas de mudança na administração pública. 
Regras para implementar uma administração com foco no cidadão

1. Envolvimento pessoal das autoridades públicas (presidentes, governadores, ministros, prefeitos, entre outros).

2. Estabelecimento de um comitê central responsável por incentivar a implementação dos projetos de mudança.

3. Responsabilização das unidades diretamente ligadas à implementação de cada projeto.

4. Concessão de autonomia para essas unidades escolherem os instrumentos a serem utilizados, o tempo e as demais características do processo de implementação.

5. Criação de um clima favorável, por meio da motivação e encorajamento dos agentes públicos, e da divulgação periódica dos resultados obtidos.

6. Distribuição de responsabilidade por equipes de trabalho nas unidades.

7. Implementação gradual das mudanças, com o devido tempo de adaptação para os cidadãos-usuários.

8. Participação nas decisões e consulta sobre soluções de obstáculos ou problemas.

9. Aprendizado e aperfeiçoamento pela experiência adquirida ao longo da implementação.

10. Controle e pressão externa, inclusive da sociedade, de forma a estimular servidores e organizações públicas a manterem forças constantes em favor da mudança.

Fonte: OCDE - Public Management Service (1996).

Finalmente, a última fase de um projeto de mudança com foco no usuário é a avaliação, ou melhor, a mensuração do desempenho dos serviços públicos. A avaliação é um componente essencial do novo modelo administrativo e baseia-se, sobretudo, na accountability dos resultados obtidos, isto é, na cobrança e na responsabilização de servidores e gerentes públicos por alguma parte do serviço prestado ao cidadão. Mais uma vez, os estudos realizados pelo CCMD (Blythe e Marson,1999) levantam uma série de sugestões e pontos relevantes aos projetos de mudança, que o trabalho se encarrega de sintetizar no quadro abaixo:

\section{Sugestões para a avaliação de serviços públicos}

1. Estabelecer metas anuais para os serviços prestados, e comparar o desempenho atual da organização com essas metas.

2. Medir as deficiências nos serviços oferecidos, em termos de satisfação dos usuários. 
3. Informar todos os servidores e gerentes sobre as metas anuais estabelecidas e transferir a eles o poder e os recursos necessários para alcançá-las.

4. Medir o nível de satisfação dos servidores e gerentes com o desempenho obtido.

5. Comunicar todas as iniciativas aos cidadãos e stakeholders.

6. Estabelecer um forte controle sobre os resultados.

7. Associar sistemas de recompensa, compensações e reconhecimento de servidores e gerentes públicos à avaliação de resultados.

8. Garantir que os sistemas de avaliação de desempenho dos serviços públicos serão sempre positivos, e não punitivos.

Apud Blythe e Marson, 1999.

\section{Modelos de atendimento single-window}

Até agora no texto, foram observadas as diretrizes gerais da administração pública voltada para o cidadão: conceitos, princípios, macroestratégias, aspectos culturais e questões amplas relativas ao planejamento, implementação e avaliação de um conjunto de projetos de mudança. Esta parte específica do trabalho, por outro lado, visa apresentar alguns modelos de atendimento mais objetivos, simples e capazes de gerar transformações bastante evidentes aos olhos dos cidadãos.

Os modelos de atendimento single-window são uma tendência internacional. O objetivo maior desses modelos é reduzir o tempo e os esforços que os cidadãos devem dispor para encontrar e obter os serviços que eles necessitam, aproximando da população os serviços públicos e as informações sobre eles (Bent et al 1999). Tendo em vista que os cidadãos querem que os serviços prestados sejam os mais acessíveis, convenientes e diretos possíveis, os modelos de atendimento singlewindow têm ganhado cada vez mais proeminência.

Atualmente, o conceito de serviço single-window é definido de uma forma bastante ampla, considerando diferentes tipos de mecanismos de gestão. Não obstante sua variedade, é possível classificar o singlewindow service em três categorias principais: centrais de informação ( gateways), centros de atendimento único (one-stop shopping) e centros de atendimento específico ( seamless service). Essa classificação foi feita recentemente, com base, sobretudo, em experiências canadenses (Bent et al, 1999).

As centrais de informação ou gateways, como são chamados originalmente, procuram melhorar o atendimento ao público disponibilizando 
mais facilmente informações e serviços por meio de centrais telefônicas, páginas na Internet e escritórios de informação geral, entre outros. Esse tipo de atendimento torna as organizações públicas mais acessíveis ao cidadão, facilitando a obtenção de informações do governo mesmo em jurisdições diferentes. Em muitas instâncias desse modelo de atendimento, cidadãos não precisam deixar suas casas, em direção às repartições públicas, para sanar alguma dúvida, solucionar problemas e, até mesmo, obter algum tipo de serviço. O principal responsável por isso é o desenvolvimento tecnológico, expresso nas telecomunicações e na informática.

Os centros de atendimento único, por sua vez, conhecidos no exterior como one-stop shopping, permitem que os cidadãos possam ter acesso a muitos ou a todos os serviços que necessitam em apenas uma localidade que lhes seja conveniente, estejam esses serviços relacionados ou não. Os centros de atendimento único podem ser físicos ou eletrônicos, isto é, podem se constituir via guichê de balcão ou via Internet. Eles acabam com uma das principais queixas de cidadãos-usuários, qual seja, a necessidade de se locomover em diferentes repartições públicas para solucionar seus problemas, quando estes poderiam ser resolvidos em um lugar somente. A conveniência desse tipo de atendimento é clara e, mais uma vez, utilizam-se os avanços tecnológicos e os meios de comunicação hoje disponíveis.

Finalmente, o terceiro modelo é o de centrais ou centros de atendimento específico. No exterior, esse modelo é geralmente chamado de seamless service porque, como o próprio nome diz, torna os serviços públicos menos complicados e embaralhados em uma rede complexa de interseções burocráticas. Esses centros de atendimento visam oferecer serviços em área específica ou para um grupo específico de cidadãos, independente das jurisdições e níveis de governo. Geralmente nesse modelo, os serviços são oferecidos cruzando fronteiras departamentais dentro de um mesmo governo, e até mesmo fronteiras governamentais que dividem união, estados e municípios.

Observa-se que em todos os três modelos de atendimento singlewindow apresentados, os serviços públicos tornam-se muito mais acessíveis, convenientes e simples. Além disso, é importante perceber também que esses modelos não são mutuamente excludentes. Ao contrário disso, freqüientemente eles são utilizados em conjunto, misturam-se e, dessa forma, surtem ainda mais efeitos positivos. Há também variações na estrutura de cada um desses modelos de atendimento. As organizações podem optar por oferecer elas mesmas os serviços ao público, podem também se juntar com outros departamentos e níveis diferentes de governo, e podem ainda delegar a prestação de serviços para outras organizações (Bent et al, 1999).

Existem basicamente dois grandes problemas e desafios impostos aos modelos de atendimento single-window. O primeiro deles está 
relacionado à tensão entre as jurisdições departamentais (turf tension), isto é, a um problema decorrente das relações administrativas intergovernamentais. A proteção dessas jurisdições freqüentemente impedem o crescimento e desenvolvimento de serviços de atendimento único ou específico. A princípio, serviços desse tipo requerem acordos entre departamentos e, às vezes, organizações de Estados e municípios diferentes. Quando uma ou mais dessas agências envolvidas não concorda em unificar os serviços prestados ao público, a implementação do modelo fica completa ou parcialmente comprometida. Uma das saídas para esse desafio de reunir vários departamentos de diferentes jurisdições, é constituir uma organização com a propriedade direta sobre a distribuição do maior número possível de serviços em uma determinada área ou setor. Isso diminui e desencoraja impedimentos impostos por outros departamentos, criando, assim, incentivos à cooperação (Bent et al, 1999).

Vale notar que as parcerias entre departamentos, principalmente as parcerias intergovernamentais, podem eventualmente causar algum problema para a implementação de modelos single-window, relacionados à accountability, à visibilidade e às políticas de recursos humanos. Por esse motivo, a implementação de novas centrais de atendimento deve assegurar, antes de mais nada, que o gestor-geral diretamente responsável por essas centrais seja sempre monitorado por um comitê gerencial composto por todos os membros parceiros. Por sua vez, cada parceiro desse comitê deve ser também monitorado pelos respectivos governos. Essa rede de controle é fundamental para garantir a responsabilização administrativa.

Ainda sob esse aspecto, outro cuidado que deve ser tomado é com o reconhecimento do papel desempenhado por cada parceiro. Isso significa que, para garantir a visibilidade do programa - a socialização das suas virtudes e defeitos - é preciso identificar e reconhecer a participação dos parceiros, evitando, assim, eventuais descontentamentos e rompimentos. Finalmente, os administradores desses programas devem evitar também iniquiidades no gerenciamento dos recursos humanos mobilizados por cada parceiro, buscando nivelar a descrição das funções, a remuneração e a capacitação de servidores das diferentes organizações e níveis de governo envolvidos no programa.

O segundo grande desafio dos modelos de atendimento singlewindow é de ordem tecnológica (technological travails). Avanços na tecnologia da informação têm facilitado bastante a criação e operação dos modelos de atendimento single-window. Porém, quando esses modelos envolvem a coordenação de diferentes organizações prestadoras de serviços, a incompatibilidade de tecnologias pode aparecer como um problema sério para a sua implantação efetiva. Outros problemas podem ocorrer com a falta de conhecimento ou consenso de qual seja a melhor tecnologia a ser empregada (Bent et al, 1999 ). 
De fato, a falta de integração dos sistemas entre as organizações e departamentos impede o bom funcionamento, principalmente, das centrais de informação. Contudo, existe outro desafio para a implantação de modelos single-window relacionados à tecnologia, qual seja, a segurança das informações e banco de dados disponíveis em redes de computadores. Junto com os benefícios trazidos pela Internet, vieram também os riscos de um ataque de vírus, invasão de hackers e assim por diante. Nesse sentido, se por um lado o estabelecimento de serviços públicos on line é um salto fantástico de qualidade, por outro, é imprescindível garantir aos cidadãos, e ao próprio governo, a proteção de informações confidenciais.

Não obstante todos esses desafios, existem grandes razões para se acreditar em uma implantação bem-sucedida dos modelos de atendimento single-window. Cidadãos desejam mudanças, e administradores públicos, cada vez mais, estão dispostos e motivados a alcançá-las. O essencial para que as reformas no atendimento obtenham êxito é evitar expectativas fora da realidade, ou melhor, não esperar resultados além das propostas centrais objetivadas. Assim, as organizações públicas não devem jamais esquecer o escopo e as metas previamente estabelecidas, seguindo passo a passo e cautelosamente no processo de mudança. Todos esses cuidados serão resumidamente descritos nas orientações finais do trabalho, apresentadas a seguir.

\section{Orientações adicionais}

A principal proposta deste texto foi apresentar o modelo de administração pública voltada para o cidadão. Foi visto que esse modelo é composto por uma série de conceitos e princípios inter-relacionados, baseados na iniciativa privada e adaptados ao setor público, que visam melhorar os serviços prestados ao cidadão, abandonando definitivamente toda a burocracia ou empecilhos para um atendimento mais simples, conveniente e acessível.

Nesse sentido, observou-se também que a nova administração pública voltada para o cidadão pode ser resumida em três elementos fundamentais. Em primeiro lugar, a qualidade do serviço é medida pela satisfação do cidadão-usuário. Em segundo lugar, os recursos de uma organização devem ser dirigidos por uma ação inovadora, capaz de encontrar soluções que viabilizem a melhoria no serviço público. E, finalmente, em terceiro lugar, o atendimento ao cidadão deve perseguir sempre um diferencial de qualidade, adotando uma cultura de prestação de serviços e um conjunto de estratégias para mudança, associados ao poder de escolha dos cidadãos. 
Para a realização desse empreendimento, são necessárias questões gerais relativas ao planejamento, implementação e avaliação de projetos com foco no cidadão. Por sua vez, experiências internacionais específicas demonstram que modelos de atendimento ungidos pela idéia de guichê único são capazes de promover transformações fantásticas e bastante efetivas. A aplicação desses modelos, como de resto toda a administração pública voltada para o cidadão, implica em adotar várias orientações, regras e instrumentos de gestão. Assim, na forma de um sumário geral, apresento a seguir alguns passos importantes que podem ajudar a orientar futuros processos de mudança, com base na literatura e experiências internacionais. Os 15 principais passos para uma organização que deseja implantar um programa de administração pública voltado ao cidadão são:

1) Incentivar a formação de uma cultura administrativa centrada no cidadão.

2) Promover mais liberdade de escolha aos cidadãos, aumentando as opções de serviços.

3) Buscar apoio e sustentação política no Congresso, na Presidência, nos Ministérios ou nas Secretarias.

4) Dispor de lideranças, formais ou informais, em todos os níveis, tanto nas altas gerências administrativas quanto dentro das organizações.

5) Planejar cautelosamente o novo programa de serviço, no curto, médio e longo prazo, e realizar um projeto piloto para experiência e eventuais ajustes.

6) Consultar stakeholders, isto é, indivíduos ou grupos que tenham interesse no desempenho do sistema ou organização.

7) Investir no treinamento de pessoal e no capital tecnológico e logístico da organização.

8) Criar parcerias baseadas na unificação de objetivos, igualdade de influência sobre as decisões, divisão equânime do reconhecimento pelo trabalho desenvolvido e nivelamento das políticas de recursos humanos.

9) Compartilhar informações sobre requerimentos tecnológicos e equipamentos de comunicação entre parceiros.

10) Divulgar e explicar as inovações planejadas, esclarecendo exaustivamente como os cidadãos podem utilizar o novo serviço e contribuir para o seu aperfeiçoamento.

11) Segmentar a base de cidadãos-usuários em grupos para identificar suas expectativas quanto a tempo e modelos de atendimento. Em alguns casos, ao invés disso, o engajamento dos cidadãos deve ser concebido em termos da comunidade como um todo.

12) Estabelecer padrões de qualidade no atendimento com base nas expectativas dos cidadãos, e compará-los com a eficiência e eficácia dos serviços já oferecidos. 
13) Medir a satisfação e percepções dos cidadãos, promovendo feedbacks por meio de uma maior variedade de instrumentos de consulta, e tendo alguém formalmente responsável e treinado em metodologia de pesquisa.

14) Monitorar constantemente a implementação do projeto, fazendo os ajustes necessários.

15) Comunicar os resultados obtidos à sociedade, às organizações e a outros departamentos do governo.

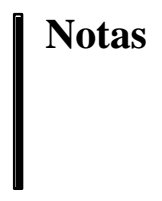

* Este texto foi elaborado como referencial teórico para o estudo "Experiências inovadoras na gestão de serviços públicos com foco nos cidadãos-usuários”, coordenado pela Pesquisa ENAP, correspondente à base conceitual para análise de experiências voltadas para a melhoria do atendimento ao cidadão-usuário dos serviços públicos, que o referido estudo pretende desenvolver.

${ }^{1}$ A preocupação com o atendimento ao público não surge somente nos anos 90 . Uma prova disso é a publicação em 1982 do documento do governo brasileiro intitulado “Atendimento novo, vida nova!”. Contudo, a mudança na orientação da administração pública voltada para o cidadão ocorre de modo consistente, com novos conceitos e práticas administrativas, somente a partir da segunda metade da década de 80 em países da OCDE, nos anos 90 no Brasil e Estados Unidos.

2 Ver Fox (1996), Carrol (1995), Iulio et al, (1993), Myers e Lacey (1996), Peters (1998) entre outros autores que criticam o conceito de cidadão como cliente.

${ }^{3}$ Há uma terceira crítica dirigida ao conceito de cidadão como cliente, ligada à subestimação da qualidade do processo decisório de políticas públicas. Como esta crítica é feita mais à participação dos cidadãos na nova administração pública, e menos à discussão sobre atendimento, preferi não debatê-la neste trabalho.

${ }^{4}$ Com base nessa definição adotada pelo trabalho, um determinado serviço do governo pode, por exemplo, beneficiar diretamente uma pequena empresa e, por sua vez, beneficiar indiretamente a população como um todo, devido ao crescimento econômico e demais ganhos associados com isso.

5 A definição da administração voltada para o cidadão aqui apresentada foi retirada do documento Citizen-Centred Service: Responding to Needs of Canadians, publicado pelo Canadian Centre for Management Development e Citizen-Centred Service Network (1999).

6 Trabalhos recentes como o de Kelly Fallon (2000), que analisa experiências de governos locais, também destacam a importância da avaliação de resultados para o sucesso da implantação de modelos administrativos com foco no cidadão.

7 Para encontrar uma lista de maneiras de se ouvir os clientes, ver Osborne e Gaebler (1994: 193195): pesquisas de opinião, acompanhamento do cliente, pesquisas comunitárias, contato com o cliente, relatórios de atendimento ao cliente, conselho de clientes, grupos de interesse, entrevistas com clientes, correio eletrônico, treinamento para atendimento ao cliente, teste demarketing, garantias de qualidade,inspetores, ombudsmen, sistemas de acompanhamento de reclamações, números DDG e caixas de sugestões. 
${ }^{8}$ BENT, Stephen; KERNAGHAN, Kenneth; MARSON, D. Brian. (1999), "Les Guichets Uniques: innovations et bonnes praticques". Rèseau au Service Axé sur les Citoyens, Centre Canadien de Gestion, mars.

9 Relatório da Segunda Reunião Internacional Anual de Serviços para o Cidadão. Colorado Convention Center, Denver, Colorado, EUA, 27 a 29 de fevereiro de 1996.

10 "Projeto Experiências Inovadoras na Gestão de Serviços Públicos com Foco nos Cidadãos-Usuários" - ENAP, 2000.

11 "Projeto Experiências Inovadoras na Gestão de Serviços Públicos com Foco nos CidadãosUsuários" - ENAP, 2000.

\section{Referências bibliográficas}

Alvariza, Alma. (1992), Manual de Atención al Público. Montevideo: Programa Nacional de Desburocratização.

Bent, Stephen et al. (1999), "Innovations and Good Practices in Single-Window Service". Canada: Citizen-Centred Service Network and Canadian Centre for Management Development.

Blythe, Marie; Marson, Brian. (1999), "Good Practices in Citizen-Centred Service". Canada: Citizen-Centred Service Network and Canadian Centre for Management Development.

BrasiL, Secretaria de Planejamento da Presidência da República. (1982), Atendimento novo, vida nova! Brasília: SEPLAN/SEMOR.

Bresser Pereira, Luiz Carlos. (1998), Reforma do Estado para a Cidadania: A Reforma Gerencial Brasileira na Perspectiva Internacional. Brasília: ENAP; São Paulo: Editora. 34.

Cardoso, Carmem; Cunha, Francisco Carneiro da. (1994), Tecnologia de Atendimento: cultura de prestação de serviço. Recife: Tecnologia Gerencial \& Informática.

Canadian Centre for Management Development. (1999), "Citizen-Centred Service: Responding to The Needs of Canadians". Canada: Citizen-Centred Service Network.

CARrol, J. (1995), "The rhetoric of reform and political reality in the National Performance Review". Public Administration Review, 55 (3), p. 302-312.

Cavalcanti, Bianor; Otero, Roberto Bevilacqua. (1997), "Novos Padrões Gerenciais no Setor Público: medidas do governo americano". Textos para discussão n. 16.

Christensen, Lars Ballieu. (1999), "Putting the Citizen at The Heart of Public Service". Document World, 4 (3), p.60-62.

Citizen's Charter. (1995), The Facts and Figures. Cm.2970. London: HMSO.

Clinton, Bill; GoRe, Al. (1995), "Putting Customer Fisrt'95". National Performance Review. Washington: DC.

Cunill Grau, Nuria. (1997), Repensando el Público a través de la Sociedad. Caracas: Editorial Nueva Sociedade; CLAD.

Dinsdale, Geoff; Marson, Brian. (1999), Citizen/Client Surveys: Dispelling Myths and Redrawing Maps. Canada: Citizen-Centred Service Network; Canadian Centre for Management Development.

Di Iulio, J., et al. (1993), Improving government performance: an owner's manual. Washington: Brookings Institution.

Doern, G. (1992), Implementing the U.K. Citizen's Charter. Ottawa: Canadian Centre for Management Development. 
Durant, Robert. (1999), “The Political Economy of Results-Oriented Management in The Neoadministrative State”. American Review of Public Administration, 29 (4), p. 307331.

DuRst, Samantha. (1999), "Better, Faster, Stronger: Government Reinvention in the 1990s". American Review of Public Administration, 29 (1).

Erin Research Inc. (1998), Citizens First. Canada: Citizen-Centred Service Network; Canadian Centre for Management Development.

Faloon, Kelly. (2000), “Customer Focus”. Supply House Times, 43(5), p.50-55.

Flynn, N. (1988), “A Consumer-Oriented Culture”. Public Money \& Management, 8 (1) p. 27-31.

Fox, C. (1996), "Reinventing government as postmodern symbolic politics". Public Administration Review, 56 (3), p.256-262.

Gilbert, Ronald et al. (1999), "Measuring Public Sector Customer Service Satisfaction". The Public Manager, winter.

Graham, Katherine; Phillips, Susan. (1999), "Citizen Engagement: Beyond The Customer Revolution”. Canadian Public Administration, 40 (2), p. 255-273.

Hirschmann, David. (1999), "Customer Service in the United States Agency For International Development". Administration \& Society, 31, p. 95-119.

Homburg, Christian. (2000), "Fundamental Changes in Marketing Organization: The Movement Toward a Customer-focused Organizational Structure". Academy of Marketing Science Journal, 28 (4), p. 459-97.

Lowery, David. (1998), “Consumer Sovereignty and Quasi-Market Failure”. Journal of Public Administration: Reserch and Theory. 8 (2), p. 137-72.

M acedo, Marcelo Ernandez. (1995), Cidadanias Relações de Atendimento no Serviço Público do Rio de Janeiro. Rio de Janeiro: FGV.

M ARTins, Luciano. (1995), "Reforma da Administração Pública e cultura política no Brasil: uma visão geral”. Cadernos ENAP. Brasília: ENAP.

Myres, R., Lacey, R. (1996), "Consumer satisfacton, performance and accountability." International Review of Administratiions Sceinces, 62 (3), p. 331-350.

Nascimento, Belmiro. (1993), Tecnologia organizacional: proposta de modelo conceitual de administração com estratégia voltada para o cliente/usuário e implicações na eficácia organizacional e na qualidade. Porto Alegre: Escola Superior de Administração Pública do Estado do Rio Grande do Sul.

Nunes, Edson. (1997), A Gramática Política do Brasil: clientelismo e insulamento burocrático. Rio de Janeiro: Ed. Zahar; ENAP.

OcDE. (1987), Administration as Service, The Public as Client, Paris: OCDE.

OcDE — Public Management Service. (1996), Putting Citizens First: Portuguese experience in public management reform. Paris: OCDE.

Osborne, David; Plastrik, Peter. (1997), Banishing Bureaucracy: The Five Strategies for reinventing government. New York: Addison Wesley.

Osborne, David; GAEBLER, Ted. (1994), Reinventando o Governo: Como o Espírito Empreendedor Está Transformando o Setor Público. Brasília: MH Comunicação; ENAP.

Peters, Guy. (1998), “Administration in The Year 2000: Serving the Client”. International Journal of Public Administration, 21 (12), p. 1759-76.

Pinto, Rogério. (1999), "Inovações no Fornecimento de Bens e Serviços Públicos". Revista do Serviço Público, 33 (1), p. 135-49.

Pleguezuelos, Clemente Talavera. (2000), "Las castas de servicios; um instrumento para la mejora de la calidad en la administración pública”. Série Síntesis n.3. Union Iberoamericana de Municipalistas.

Quatrebarbes, Bertrand de. (1996), Usagers ou Clients? Marketing et Qualite dans les Services Publics. Paris: Les Editions D’Organization. 
Ramos, Danielly Silva. (1997), "Sistemas de Atendimento ao Cidadão: experiências brasileiras. Relatório Interno. Brasília: ENAP.

Relatório da Segunda Reunião Internacional Anual de Serviços para o Cidadão. (1996), Colorado Convention Center, Denver, Colorado, EUA.

RuA, Maria das Graças. (1999), “Administração Pública Gerencial e Ambiente de Inovação: o que há de novo na Administração Pública Federal Brasileira", in Petrucci, Vera; Schwarz, Letícia (orgs), Administração Pública Gerencial: a Reforma de 1995. Brasília: Editora da UnB; ENAP.

SARAIVA, Luiz; CAPELÃo, Luiz. (2000), “A nova administração pública e o foco no cidadão: burocracia x marketing". Revista da Administração Pública. 32 (2), p. 59-77.

Simmons, John. (1999), "Customer Service: It's elementary". The Journal For Quality and Participation, 22 (2), p. 50-54.

Shiozawa, Ruy. (1993), Qualidade no Atendimento e Tecnologia de Informação. SãoPaulo: Editora Atlas. 


\section{Administração pública voltada para o cidadão: quadro teórico-conceitual}

\section{Marcelo James Vasconcelos Coutinho}

Jul-Set 2000

O texto apresenta um levantamento da literatura atualizada, nacional e internacional, sobre a administração pública voltada para o cidadão, constituindo, assim, um quadro teórico-conceitual do tema. Observou-se que a administração pública voltada para o cidadão é composta por uma série de conceitos e princípios inter-relacionados, baseados na iniciativa privada e adaptados ao setor público, que visam melhorar os serviços prestados ao cidadão, abandonando definitivamente toda a burocracia e empecilhos para um atendimento mais simples, conveniente e acessível.

\section{Administración pública orientada hacia el ciudadano: cuadro teórico-conceptual Marcelo James Vasconcelos Coutinho}

El texto presenta una revisión de la reciente literatura, nacional e internacional, sobre la administración pública orientada hacia el ciudadano, constituyendo un cuadro teóricoconceptual del tema. Se ha tenido en cuenta que la administración pública orientada para el ciudadano es compuesta por un conjunto de conceptos y principios relacionados entre si, sustentados en la iniciativa privada y adaptados al sector público, con vistas a mejorar los servicios prestados a los ciudadanos, abandonando toda la burocracia e impedimentos para un atendimento mas simples, conveniente y accesible.

\section{Citizen-Centred Service: theoretic-conceptual approach}

\section{Marcelo James Vasconcelos Coutinho}

The paper shows a revision of a recent bibliography, national and international, about the Citizen-Centred Service, composing than a theoretic-conceptual approach of the subject. It was observed that the Citizen-Centred Service is compound for a set of cross concepts and presuppositions, based in the private action and adapted in the public sector, that have as an objective improve the citizen's services, abandoning definitively all bureaucracy and obstruction for a simpler more convenient and accessible service.

Marcelo James Vasconcelos Coutinho é bacharel em Ciência

Política, consultor e mestrando em Relações Internacionais no Instituto de Ciência Política da Universidade de Brasília. 